\title{
To exit or not to exit: Evaluating a case management pathway in a Global South context to decrease service dependency.
}

Lee Henley ${ }^{1}$, Emily Thompson², Sreyrath Thou ${ }^{1}$, Sonthea Pheun ${ }^{1}$, Zoey Henley ${ }^{1}$, Nicky Stanley-Clarke ${ }^{3}$, Tineke Water ${ }^{4}$. .

1) Children's Future International, Cambodia

2) Mercy Community, Australia

3) School of Social Work, Massey University, New Zealand

4) Department of Research, University of Puthisastra, Cambodia

5) School of Nursing, AUT University, New Zealand

\section{Abstract}

An evaluation was undertaken of a case management pathway for a child protection organization in Cambodia to decrease service dependency. Save the Children's 'Steps to Protect' was used as an evaluation framework to identify how the organization met the criteria for the core components of case management. These included identification and initial screening, case planning, implementation, and case review, and the findings show that a well-defined, staged process for case management actively reduces service dependency. The recommendations are that a staged case management pathway should be developed in child protection services as an approach for reducing service dependency.

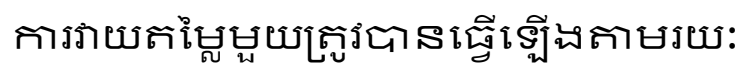

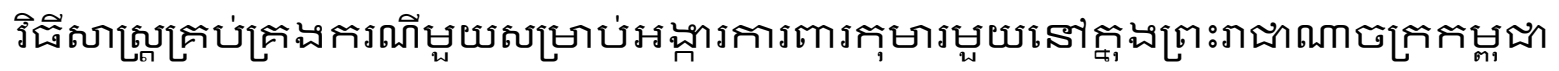

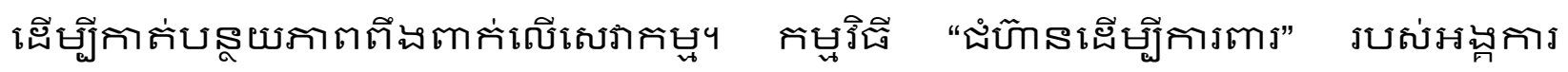

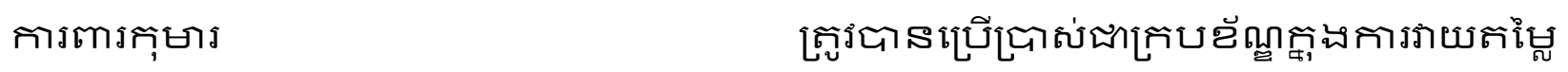

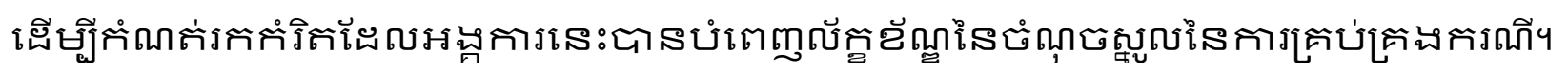

\footnotetext{
${ }^{1}$ Corresponding author Lee Henley, Children's Future Cambodia. lee@childrensfuture.org
} 


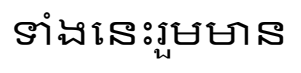

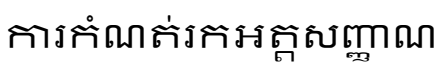

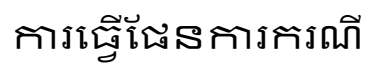

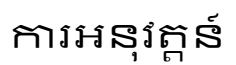

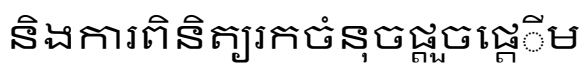

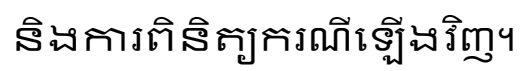

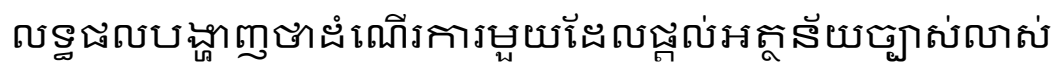

ริฟยง

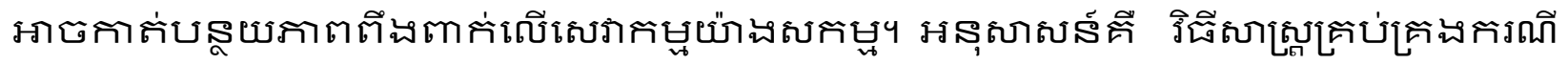

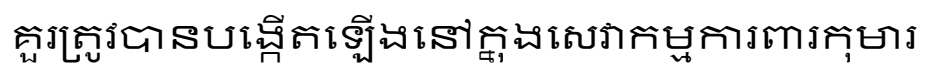

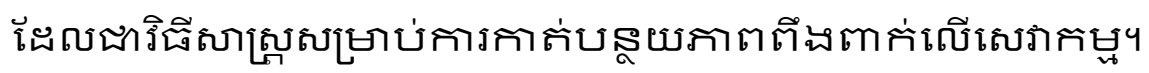

Key words: service dependency; case management; child protection; Steps to Protect. 


\section{Introduction}

In 2018, in response to concerns around service dependency, Children's Future International (CFI), a child protection NGO, introduced a case management pathway. In 2019, an evaluation was undertaken of CFl's case management pathway using Save the Children's Steps to Protect framework. This review focused on client entry and exit from the service. The aim of the evaluation was to investigate whether a case management pathway could provide an effective strategy in reducing service dependency for families and the service providers.

\section{Background}

Founded in 2009, CFI is an NGO focused on supporting children and youth to break the poverty cycle through educational programs and community support. These programs are offered within a community experiencing poverty, malnutrition, unsafe migration, exploitative labor practices, physical and sexual abuse, and secondary PTSD (generational) from the Khmer Rouge genocide in the 1970s. CFI is part of two national child protection networks; Family Care First/REACT (FCF/REACT, 2019) and 3PC (The Partnership Program for the Protection of Children). FCF/REACT, led by the Ministry of Social Affairs, Veterans and Youth Rehabilitation (MoSVY), is a network of over 60 organisations, financially supported by the European Union, USAID, the GHR Foundation, Save the Children Hong Kong and UNICEF. They aim to support more than 7,000 Cambodian children to live in safe, nurturing, family-based care. 3PC (2019) is a Cambodian child protection program powered by Friends-International (FI) in collaboration with UNICEF and the Cambodian Ministry of Social Affairs, Veterans and Youth Rehabilitation (MoSVY).

In its early years, CFI was a residential care institution, before realizing it was better for children to be supported in community family-based settings. This shifted the focus to supporting other residential care institutions to adopt community-based approaches and reintegrate children back into the community. Although community integration programs have been successful, in 2018 a new problem was identified - that of service dependency. Two main contributors to this were identified. Firstly, the organization focused on the entry 
of clients into the service but did not have a well-defined case management plan that included a transition or exit plan. Children, young people, and families entering CFI were assessed by a single staff member who would then allocate a range of services. Although this practice was intended to provide a holistic approach, it meant clients often received unnecessary services. Secondly, funding for CFI and service provision was based on the number of people in the service, rather than outcome measures that included successful transition out of the service. The consequences of these approaches meant many children, young people and families were held in the service, meaning other at-risk children, young people, and families were unable to access the much-needed resources. Child protection services are often focused on solving problems. However, the case of CFI highlighted that a new problem is inadvertently created if these services are not tailored to the individual/community.

\section{Literature review - service dependency and case management}

Since 1993, civil society organizations have played an important role in Cambodia to support meeting the 2000 Millennium Development Goals (MDGs) and 2012 Sustainable Development Goals (SDGs). Although there is a strong culture of community-based programs in the Global South, such as in Cambodia, providing a coordinated approach is often hampered by lack of infrastructure, and weak education, health, and social systems (UNDP, 2013). Efforts to improve health and social outcomes for people in Cambodia through improving infrastructure and governance are often hampered by the involvement of multiple actors from diverse backgrounds and differing agenda. Cambodia has one of the highest number of NGOs in the world, with approximately 3000 NGOs in 2020 (CCC, 2020).

Countries in the Global South are generally referred to as "developing". In terms of social work knowledge, the Global North (made up of countries with predominately western values and views) largely ignores the context of the Global South when defining practice (Roche \& Flynn, 2020). Few authors have commented on the challenges for developing a case management pathway within child protection organizations in a Global South context. Those who do discuss the double bind of generating a system that works within 
complex environments, compounded by the impact of globalization where the gaps between economic growth and social problems are widening and where local contexts, values and knowledge may not be valued (Tsui \& Yan, 2010). Strydom and Schiller (2019) argued that social, political, and cultural contexts are important for ensuring applicability and relevance when transferring tools across different cultural and ethnic groups. Yet, avoiding the privilege of Western paradigms is both difficult and challenging.

Increasingly, in the Global South, it has been questioned whether organizations are engaging in development or creating dependency (Sahoo, 2013). Harvey and Lind (2005) argued that the word 'dependency' is widely used in development discourses. However, the meaning is less clearly defined and may reinforce Western understandings and positions. Harvey and Lind (2005) suggest that dependency has been constructed by different discourses which guide thinking on dependency in particular ways, and where those with power (i.e., donors) frame discussions around the impact of aid on those without power (i.e., those receiving support). Aid organizations may also become dependent on donors for ongoing funding, which may then frame the way the organizations works and organizational outcomes.

At the level of NGOs, where the funding is tied to the number of people within the service, rather than focusing on successful transition of clients out of the service, service dependency is often influenced by the political agenda of funders. This provides little or no incentive to ensure services move people through the system, supporting clients' autonomy and independence. Child protection interventions can have a negative impact on children and families, particularly when the family becomes dependent on the services provided (Harnett \& Day, 2008).

Lack of clarity over what changes a family may need to make and/or a lack of robust plans can lead to negative learned behaviors. This is particularly true where families continue to rely on guidance from the 'experts' rather than having autonomy over their decisionmaking (Harnett \& Day, 2008; Drewery \& Claiborne, 2014). Where clients cannot do things themselves, unintended messages to clients may result in feelings of 
disempowerment rather than empowerment (Cooper 2012). Dependency then arises because of unequal, asymmetrical, and paternalistic relationships, when instead partnerships based on equality, mutual respect, joint activity, and joint learning, are needed to achieve better outcomes (Strier \& Binyamin, 2013). Stanford (2015) argues that aid and service provision are also often tied to 'best practice' policies that do not consider local contexts. This results in top-down, homogenous approaches that do not acknowledge important constructs such as values, beliefs and social values, or the infrastructure needed to effectively implement the programs.

In child protection, the characteristics of case management have been described as assessing a child, youth and family's problems and needs; planning, referring, and providing the appropriated resources they need; alongside their participation and provide ongoing support (Hall, Carswell, Walsh, Huber \& Jampoler, 2002). UNICEF describes case management as a systematic, timely approach that serves to assess the needs of a client by arranging, coordinating, monitoring, evaluating, and advocating for client needs through case plans (UNICEF, 2017). Save the Children defines case management as a "process of assisting individual children and families through direct support and referral to other services by social workers and other staff to address their social and protection needs" (McCormick, 2011, p.1). In September 2017, Save the Children launched the best practice guidelines of Steps to Protect, for use of Save the Children and partner agencies within Global South contexts (Save the Children, Quality Benchmarks, N/D). The Steps to Protect guidelines for case management include identification and assessment; individual support planning; referral and liaison with support services; monitoring and review; and case closure (McCormick, 2011).

The aim of this evaluation was to evaluate CFI's current service delivery strengths, identify areas for development; and explore how (or if) the new case management pathway contributed to decreased service dependency. 


\section{Study Design}

A mixed method approach was used by the research team to evaluate CFl's case management processes:

- The Steps to Protect practice guidelines were used as a framework for data collection and analysis. This included a desktop review of CFl's documents (guidelines, policies, and processes).

- Discussions with CFl's staff and stakeholders. In this instance, the stakeholders were a Consumer Advocacy Group of adults who offer CFI advice as to what services are working well and which requirement improvement. This group is comprised of predominately family members of young people using CFl's services who consented to participate. Staff conversations took the form of semistructured discussions, which were optional. It was made clear to staff they were not required to participate.

- Observations in the field were also conducted which were then ranked by the researchers against the Steps to Protect practice domains.

Domains were ranked into four categories, 'good practice', 'meets minimum levels', 'requires improvement' or 'critical to address'. The domains included in the framework were:

1. Case management response

2. Case management process

a. Identification and registration

b. Assessment

c. Care planning

d. Care plan implementation

e. Follow up and review

f. Care closure

3. Strengthening the child protection system

4. Collaboration and coordination

5. Appropriate staffing and child protection systems

a. Safeguarding and do no harm 
b. Competencies, skills, and experience

c. Capacity building

d. Supervising and coaching

6. Sufficient financial, material, and logistical resources

7. Information management for case management

8. Monitoring, accountability, and learning

Ward (2011) argued that an evaluation should not only document what is currently being done, but also contribute to the integration of strategies and interventions that will help improve an organization or service. The Steps to Protect framework allows for identification of areas for improvement, whilst simultaneously identifying future actions. While all domains were assessed, as this study was focused on service dependency, the first two domains of case management response and process were of concentrated interest. The other domains were also ranked and contributed to an organizational report. Once assessed and ranked, areas for improvement were identified and planning undertaken for what interventions/strategies would be needed to move a domain towards meeting 'best practice'.

A final year social work student from Griffith University in Australia collected and collated the data. Emily spent three months in Cambodia on placement at CFI, which gave her the opportunity to become familiar with the service, build trust with CFI staff, and provide an 'outsider' view on the service that was perhaps less influenced by any vested interests. Although insider research provides a rich view from the inside, as the researchers understand the complexities and nuances of an area of interest, this can also lead to assumptions because of what is already known. Having an outsider who nevertheless was closely aligned with the service ensured that a variety of perspectives would be included.

Once the data had been reported under the appropriate domain, the researchers identified themes and compared these to best practice examples outlined in Save the 
Children's Common Goals approach as well as other relevant literature. Braun, Clarke, Hayfield and Terry (2019) described this as a process of thematic comparison.

Ethical review is a contentious issue in many Global South contexts, as the review mechanisms do not exist in social science research. However, the proposed project was reviewed by academics with a background of ethical review/ethics committees in university settings both in Cambodia and internationally, and the principles of respect, confidentiality, informed consent were upheld throughout the evaluation. Although procedural ethical review and situational ethics is justifiably focused on preventing any harm (protection), equally CFI was aware of the importance of ensuring that as many people as possible had the opportunity to have a say in the evaluation, therefore upholding the important principle of participation.

\section{Findings}

The ranked desktop review results, guided discussions and observations are presented in tables below. Table One presents the findings regarding the Case Management Response, with a focus on Standard Operating Procedures. This finding demonstrated that CFI did not meet the required standard in this domain, and this area was critical to address. Table Two presents the findings regarding the Case Management Process with six subsections: Identification and registration, assessment, care planning, care plan implementation, follow up and review and case closure. This second domain's subsections produced a range of outcomes, some of which indicate a good level of practice, some demonstrating the need for attention. 


\begin{tabular}{|l|l|l|l|l|}
\hline \multicolumn{2}{|l|}{ Table 1 Case management response } \\
\hline & $\begin{array}{l}\text { Good practice } \\
\text { indicators }\end{array}$ & $\begin{array}{l}\text { Meets minimum } \\
\text { levels indicators }\end{array}$ & $\begin{array}{l}\text { Requires } \\
\text { improvement } \\
\text { indicators }\end{array}$ & $\begin{array}{l}\text { Critical to address } \\
\text { indicators }\end{array}$ \\
\hline $\begin{array}{l}\text { Standard } \\
\text { Operating }\end{array}$ & $\begin{array}{l}\text { SOPs are } \\
\text { developed multi- } \\
\text { agency wide; they } \\
\text { are recognized in } \\
\text { law and reviewed } \\
\text { every } 6 \text { months. }\end{array}$ & $\begin{array}{l}\text { SOPs are } \\
\text { developed intra- } \\
\text { implemented and } \\
\text { monitored. }\end{array}$ & $\begin{array}{l}\text { SOPs exist and are } \\
\text { monitored. }\end{array}$ & $\begin{array}{l}\text { Outcome of } \\
\text { review: SOPs do } \\
\text { not exist. }\end{array}$ \\
\hline
\end{tabular}

\begin{tabular}{|c|c|c|c|c|}
\hline & $\begin{array}{l}\text { Good practice } \\
\text { indicators }\end{array}$ & $\begin{array}{l}\text { Meets minimum } \\
\text { levels indicators }\end{array}$ & $\begin{array}{l}\text { Requires } \\
\text { improvement } \\
\text { indicators }\end{array}$ & $\begin{array}{l}\text { Critical to } \\
\text { address } \\
\text { indicators }\end{array}$ \\
\hline $\begin{array}{l}\text { Identification and } \\
\text { registration }\end{array}$ & $\begin{array}{l}\text { Cases can be } \\
\text { identified and } \\
\text { referred for case } \\
\text { management } \\
\text { through } \\
\text { established } \\
\text { pathways. } \\
\text { Communities } \\
\text { proactively } \\
\text { involved. }\end{array}$ & $\begin{array}{l}\begin{array}{l}\text { Outcome of } \\
\text { review: }\end{array} \\
\text { Cases can be } \\
\text { identified and } \\
\text { referred for case } \\
\text { management } \\
\text { through } \\
\text { established } \\
\text { pathways. }\end{array}$ & $\begin{array}{l}\text { Cases are } \\
\text { identified in an } \\
\text { ad-hoc manner. }\end{array}$ & $\begin{array}{l}\text { No system for } \\
\text { identifying cases } \\
\text { in need of child } \\
\text { protection case } \\
\text { management. }\end{array}$ \\
\hline Assessment & $\begin{array}{l}\begin{array}{l}\text { Outcome of } \\
\text { review: }\end{array} \\
\text { Always } \\
\text { completed using } \\
\text { set format. Risks } \\
\text { and protective } \\
\text { factors are } \\
\text { always } \\
\text { considered. }\end{array}$ & $\begin{array}{l}\text { Always } \\
\text { completed using } \\
\text { set format. }\end{array}$ & $\begin{array}{l}\text { Assessments } \\
\text { completed, but } \\
\text { no set format. }\end{array}$ & $\begin{array}{l}\text { Assessments not } \\
\text { completed. }\end{array}$ \\
\hline
\end{tabular}




\begin{tabular}{|c|c|c|c|c|}
\hline Care planning & $\begin{array}{l}\text { Case plans } \\
\text { completed using } \\
\text { set format. } \\
\text { Short, medium- } \\
\text { and long-term } \\
\text { needs, and risks } \\
\text { included. }\end{array}$ & $\begin{array}{l}\text { Outcome of } \\
\text { review: } \\
\text { Case plans } \\
\text { completed using } \\
\text { set format. } \\
\text { Needs and risks } \\
\text { included. }\end{array}$ & $\begin{array}{l}\text { Case plans are } \\
\text { completed but no } \\
\text { set format used. }\end{array}$ & $\begin{array}{l}\text { Case plans are } \\
\text { not always } \\
\text { completed. }\end{array}$ \\
\hline $\begin{array}{l}\text { Care plan } \\
\text { implementation }\end{array}$ & $\begin{array}{l}\text { Best practice } \\
\text { achieved. Case } \\
\text { worker updates } \\
\text { referral details. } \\
\text { Consent is } \\
\text { always sought, } \\
\text { and information } \\
\text { shared is on a } \\
\text { need-to-know } \\
\text { basis. Family is } \\
\text { supported to } \\
\text { attend services. }\end{array}$ & $\begin{array}{l}\text { Outcome of } \\
\text { review: } \\
\text { Case worker } \\
\text { updates referral } \\
\text { details. Consent } \\
\text { is always sought, } \\
\text { and information } \\
\text { shared is on a } \\
\text { need-to-know } \\
\text { basis. }\end{array}$ & $\begin{array}{l}\text { Basic details are } \\
\text { followed up. Case } \\
\text { worker is aware of } \\
\text { referral options } \\
\text { and consent is } \\
\text { sought. }\end{array}$ & $\begin{array}{l}\text { Case plans are } \\
\text { not followed up } \\
\text { on. }\end{array}$ \\
\hline $\begin{array}{l}\text { Follow up and } \\
\text { review }\end{array}$ & $\begin{array}{l}\text { Outcome of } \\
\text { review: } \\
\text { Regular follow } \\
\text { ups are recorded } \\
\text { in case notes } \\
\text { family } \\
\text { information } \\
\text { gathered as part } \\
\text { of set format. }\end{array}$ & $\begin{array}{l}\text { Regular follow } \\
\text { up achieved, } \\
\text { with set format } \\
\text { followed. }\end{array}$ & $\begin{array}{l}\text { Regular follow up } \\
\text { achieved, but no } \\
\text { set format } \\
\text { followed. }\end{array}$ & $\begin{array}{l}\text { Regular follow } \\
\text { ups not } \\
\text { completed. }\end{array}$ \\
\hline Case closure & $\begin{array}{l}\text { Cases closed on } \\
\text { clear criteria and } \\
\text { a three-month } \\
\text { post closure } \\
\text { meeting ensures } \\
\text { child is safe. }\end{array}$ & $\begin{array}{l}\text { Outcome of } \\
\text { review: } \\
\text { Cases closed on } \\
\text { clear criteria as } \\
\text { required. }\end{array}$ & $\begin{array}{l}\text { Criteria for } \\
\text { closure in place, } \\
\text { but cases closed } \\
\text { in ad-hoc manner } \\
\text { or left open. }\end{array}$ & $\begin{array}{l}\text { No clear criteria } \\
\text { for case closure } \\
\text { or cases left } \\
\text { open. }\end{array}$ \\
\hline
\end{tabular}




\section{Discussion of findings}

This section presents a discussion of the findings regarding domains 1 and 2 and subsections where relevant.

\section{Domain 1: Case Management Response}

One of the key components of case management is the implementation of Standard Operating Procedures (SOPs). SOPs provide documented processes that ensure services are delivered consistently in a manner which reduces the likelihood of errors (Pearce, 2019). Steps to Protect clearly states that SOPs for child protection case management should be developed through an inter-agency process (e.g., through a national Case Management Coordination Group) and be formally recognized in law, with their implementation monitored. Steps to Protect guidelines also state that the SOPs must be updated and shared at least every six months (Save The Children $n / d$ ). In a review of services in Cambodia, Lao and the Solomon Islands, Save The Children highlighted the need for organizations like CFI to strengthen and work together to contribute to national processes on child protection systems (Save The Children, 2014). CFI found that despite this recommendation in 2014, this was an area that CFI has not yet achieved at the time of the evaluation. Since then, SOPs have been established at CFI.

SOPs are described as a set of clear instructions/processes that help people within an organization carry out complex but routine tasks. It is argued that SOPs are designed to improve efficiency, certainty, quality, and uniformity of performance by providing a set of standardized processes that reduce waste, increase workplace efficiencies, and streamline work processes (Akyar, 2012). By standardizing processes, it is envisioned that all members of the organization have a clear idea of what is expected to prevent children and families from falling through the gaps. For $\mathrm{CFI}$, this would support reducing service dependency as staff feel more confident in exiting families from the service when risks are lowered.

One of the criticisms of standardization via SOPs is that it takes a 'command and control' approach where the experts know best, and where targets drive quality and performance indicators (Featherstone, White \& Wastell, 2012). This was evident in the previous 
standard processes at $\mathrm{CFI}$, which relied on referring families to as many services as possible to provide a holistic approach, and success was measured in the uptake of services rather than families no longer needing them.

A challenge for $\mathrm{CFI}$ is to ensure that the future SOPs do not become another set of processes that may have unintended consequences for the community. Featherstone, White and Wastall (2012) argued that SOPs should incorporate processes with a set of sequential steps including what is recorded; and that practices should focus on the analytical ability to interpret situations alongside trusting relationships between staff and families. This provides standardized processes mediated by human and social factors. Therefore, for CFI it will be important to implement standardization while focusing on transparency and decision-making within the organization, accounting for complex work within streamlined organizational processes.

Local cultural understandings of child rearing, child protection, risk, danger, and worry are important to any child protection initiatives. Therefore, including communities' views, local systems and approaches should be built into a service (Save the Children, 2014). CFI has begun this process by including children, families and local authorities in discussion and decision-making on individual child protection cases. This is important as children grow up in families and communities and should also have a role to play in making decisions on things that involve them (Freeman, 2009). Morris and Connolly (2012) argued working in partnership increases children's safety nets through collaborative discussions and decision-making on individual child protection cases. This also has the benefit of strengthening family decision-making and preserving local community authority responsibility (Harnett \& Day, 2008; Drewery \& Claiborne, 2014).

Cultural considerations inform the social context of child rearing in Cambodia. In Khmer culture, child rearing is often intergenerational and communal. Many cases referred to CFI were related to parents abandoning children with grandparents either due to remarrying or economic migration. This puts pressure on older people often facing economic insecurity themselves. A positive aspect of communal involvement in child 
rearing was that the wider community made referrals. This differs from Western notions of the nuclear family, where full responsibility remains within the family. Fronek et al. (2019) found that children's connections with the wider community were essential in reintegrating children back into families, and an important first step in a child protection system.

The lack of local communities' perspectives and involvement in decision-making has not only impacted culturally appropriate service delivery, but also prevented NGOs from engaging in meaningful civic engagement and social accountability (Malena, et al., 2009). CFI has started moving towards a Khmer-run organization underpinned by Khmer knowledge, practices, and expertise. This includes awareness of how meetings or discussions are run, who chairs and who participates in the meetings and how decisionmaking is based on Khmer cultural perspectives and jurisdictions, rather than interjecting Western views (which may or may not be appropriate). Wider community inclusion has also been a strategy to strengthen service delivery and decrease service dependency. As village chiefs have input into child protection matters, frequently making decisions for families, they provide valuable insights and ongoing support for families entering and exiting the service. Involving the community is important so that organizations can provide capacity building for local staff while providing sustainable systems within communities and local social and political systems (Barron et al., 2012). Whilst community engagement, partnership and ownership of interventions are important, this is not to say that issues such as patriarchy or internal conflict may also impact on communal decisionmaking processes.

\section{Domain 2: Case management process}

a) Identification and registration - minimal criteria met.

CFI met the minimal criteria for identification and registration, which are that cases can be identified and referred for case management through established pathways. Currently CFI has a range of referral routes such as local authorities and government departments. When a family is referred to the service they are registered, and an assessor carries out an assessment of the family's views, strengths, and needs. Strength-based practice 
highlights the importance of strengthening protective factors. Focusing on protective factors strengthens childcare and child nurturing skills within families (Ferenczi, Csákvári \& Tánczos, 2015) promoting change, reaching goals, growing independence, and providing hope in individuals and communities (Pulla, 2017).

Each case is presented at an inter-disciplinary meeting and a case manager assigned to work with the family throughout their engagement with the service. This promotes a multidisciplinary approach to care co-ordination as advocated by WHO (2018) as well as effective communication between the team and clients (Ross, Curry, \& Goodwin, 2011). Approaching cases from an inter-disciplinary approach has also been useful in facilitating discussions around risk and which cases should be prioritized and accepted. Decisionmaking around risk can have significant impact. Case workers use the information they gather to make sense of risk, making decisions which frequently come under great criticism (Stanley, 2013). The challenges of any child protection risk assessment are the assumption that accurate risk prediction is possible (Gillingham, 2006). Thus, it is important that cases are discussed, decision-making shared, and transparency maintained, all of which contribute to trust within the team. There also needs to be a balance between managing a risk that could occur in the future, and the actual events of child harm occurring now, to direct resources appropriately (Stanley, 2013). For any organization, having clear criteria around risk is paramount. This occurs alongside balancing child and family safety with the available resources of the organization. Overreferral is also a risk and is one that can stretch resources that might be managed more appropriately through other means.

For $\mathrm{CFI}$, managing these risks means doing so in a multidisciplinary panel setting where responsibility is shared. Having a multidisciplinary approach, via joint decision-making, also develops confidence in the pathway itself and ensures consistent approaches and decision-making (Child Welfare Information Gateway, 2019). Areas for future improvement include further involvement of the community in initiatives such as peer, parent, or elder support for parent's and supports creating collaborative community-based child protection systems (Waldfogel, 1998). 


\section{b) Assessment - best practice criteria met.}

CFI met the criteria of best practice in this domain's subsection. The initial assessment of children and families is undertaken using the Child Status Index (CSI), modified by the addition of strength- based questions, which covers six basic domains: nutrition, housing, health, education, psychosocial development, and protection (Measure Evaluation, 2019). Although there are relatively few validation studies on this tool, if used in conjunction with other tools it has been found to be effective (Cannon \& Snyder, 2012). In conjunction with CSI, CFI uses Signs of Safety (2019) and Partnering for Safety (2020) tools/surveys. Both focus on identifying family strengths and supporting families in identifying safety goals. This helps build family resilience and supports families to be a part of designing their own support systems, not simply providing services decided for them, or services which are not needed (Carter, 2019).

Implementing the use of Consent Forms as best practice has also been an opportunity to clarify the expectations for both client and service provider about the rights and responsibilities of each party. The Consent Form is a clear statement regarding the family's responsibilities for achieving mutually agreed goals and CFI's role in supporting this. As families are enrolled in the service for 6 months (which may be re-negotiated), the Consent Form provides clear guidance around expectations and end goals. Focusing on discharge from the service at the point of admission reduces the risks of service dependency, while also supporting strength-based models for family intervention (Harnett \& Day, 2008). A lack of a clear plan on admission can contribute to reliance on the service and feelings of helplessness creating a learnt behavior of need for, or dependency for, guidance and survival (Drewery \& Claiborne, 2014).

\section{c) Case Planning - minimum criteria met.}

CFI met the minimum criteria scoring on the domain for Case Planning. This meant that case plans were completed using a set format including needs and risks. However, to move to a score of best practice, short, medium, and long-term needs also need to be considered within the realities of available resources. CFI relies on donor funding, and cannot provide services to every family referred, meaning that only children of the highest 
need are the ones identified for assessment and support. Families with lower risk, or those not meeting criteria, are referred to local authorities and support mechanisms in the community. As is frequently the case in resource-poor environments, there is insufficient infrastructure to meet all identified needs, poor service delivery and a workforce limited in its capacity (Fronek, et al., 2019). This makes decision-making about who will receive services fraught in cases where there is need, but not adequate resourcing. Social determinants also need addressing these contribute to families' health and wellbeing that are often beyond the resources of a single NGO.

\section{d) Care Plan Implementation - minimum criteria met.}

CFI met the minimum criteria for this domain's subsection of care plan implementation, which included referral updates by a caseworker, consent sought (as previously discussed) and information shared on a need-to-know basis. Having a staged pathway which includes entry and exit from the service, has contributed to an overall practice culture change, where staff now assume families require the shortest intervention required to reduce risks. A staged pathway is important in a Global South context where there has been a history of problem-solving for families, often resulting in dependency on services (Harnett \& Day, 2008, Henley et al., 2019). This is especially true in the absence of clear plans and interventions, which can disempower families with messages indicating they cannot support themselves (Cooper, 2012).

One of the key elements of a strengths-based pathway is family-led decision-making. This supports recent models of health and social wellbeing and considers the voices of clients in the planning, implementation, and evaluation of services (Caceres et al, 2016). This approach values the input of families around the risks and safety of their children while working in partnership with them to promote positive outcomes. Increasing decisionmaking between child protection services and families has been shown to be effective in increasing social safety-nets for children (Morris \& Connolly, 2012). Supporting parents to be experts regarding their own solutions builds their existing strengths and resources (Rogers \& Parkinson, 2018). 
Sharing decision-making with families can be perceived as risky by organizations and may leave case managers feeling personally responsible (Stanley, 2013). This has been mitigated at CFI through regular case reviews, and consultation with the team and wider community, as well as ensuring case managers have access to regular peer review and support. This is important to avoid creating an environment of fear and blame if situations go wrong, which can result in systems where workers are unlikely to assess any situation as low risk, for fear of attracting risk themselves. The most successful way to achieve this is to be able to hold discussions within a non-blame culture (Stanley, 2013).

\section{e) Follow up and review - best practice met.}

CFI met the best practice scoring for this domain's subsection of follow-up and review. This included providing regular follow-ups which recorded family information in a structured format within the case notes. Regular case review results in lowered risks for families (Morris \& Connolly, 2012). For CFI, the use of the Child Status Index tool and multi-disciplinary panel group to share decisions about risk provided clear guidelines and recommendations for best practice.

\section{f) Case Closure - minimum criteria met.}

CFI met the minimum standard in this domain' subsection, with a clear criterion in place to close cases. The current criteria for exiting families are that family risk has been "substantially reduced" meaning the family can ensure the safety of their children without NGO support. Any risk to children remains an overriding concern, balanced with moving families away from dependency on services. Including a three-month post-closure meeting to ensure a child remains safe and families have adequate community support and resources would contribute to moving CFI closer to best practice.

Retention, or lack of case closure, has also been influenced by funding models. Previously case managers' workloads were hard to manage due to their size, as families never left CFI services. Changing the service delivery model to one that includes 'case closure' as an essential outcome measure has decreased service dependency and increased the effective management of resources at CFI. Establishing a clear case management pathway has not required an increase in funding as it did not require extra 
services. Rather, it created a shift in practice, culture, and systems where resources were more effectively allocated, risks clearly identified, and services provided in a way to increase family autonomy and independence before exiting the service.

Arguably the biggest influence on case closure at CFI has been the focus on discharge planning from the moment families enter the service. This has ensured a consistent goal

of exiting families from the service from the point of entry and providing services along the way that develop family strengths in managing the risks and stressors that face them. These strategies have all contributed to decreasing service dependency and increasing case closure. A key outcome of this research is that in the quest for case closure, families do not exit the service feeling unsupported. It is also important that funders also do not just fund on 'number in the service' but include meaningful outcomes which include successful transition out of the service.

\section{Limitations and strengths of evaluation}

A limitation of this study is that the desk-top review, discussions, and observations were undertaken by researchers who did not all speak Khmer. This can potentially provide fertile ground for comments to become lost in translation. Although Khmer CFI staff contributed to the research and reviewed/contributed to this paper, ideally any future evaluation will be Khmer-led. Another limitation of the study is that although a representative group of service users were asked to contribute their views for this review, it cannot be assumed that these represent the views of all people who use CFI services. This group was CFI's Consumer Advocacy Group, comprised of family members of the young people using CFI services. They regularly provide advice and feedback regarding quality of services, and are a constant group of volunteers who, over time, have become comfortable in providing CFI with constructive feedback. Reflexivity by the research team, member-checking, triangulation, and an audit trail, all contributed to the trustworthiness of this evaluation alongside. The Group also contributed to knowledgebuilding on the topic of reducing service dependency in a Global South context. 


\section{Recommendations for practice}

Outcomes measures, emphasizing successful case closure are necessary to address service dependency issues. The completion of clear Standard Operating Procedures, and a robust consumer participation process is integral to this approach. Further research on the interrelationship of existing child safety risk assessment frameworks and cultural relevance is needed to ensure both child safety and community applicability. The following specific recommendations are made for other organizations concerned with issues around service dependency.

1. Case Management Practice

This study demonstrates the benefit of including discharge planning or case closure from the point of service entry to decrease service dependency. Organizations should include case closure with a staged approach to case management; ensure case management pathways are based on clear and transparent SOPs; ensure that case management includes all members of the interdisciplinary team, families, and community representatives/advocates where appropriate; and that it is culturally sensitive and appropriate and support a strengths-based and partnership model for working with families. These are all important steps in decreasing service dependency in child protection organizations.

2. Shared Case Management Understandings Staff and clients should have a clear understanding of organizational case management pathway including how and why decisions are made so that autonomy rather than dependency is promoted.

3. Service Delivery and Case Management Evaluations Finally, all evaluations on service delivery and case management must include outcome measures around case closure and decreasing service dependency.

4. Further Research

More research should be undertaken to understand family, community, cultural and organizational notions of risks and compare these against risk assessment frameworks to cultural relevancy and appropriateness whilst maintaining the safety of all children. 


\section{Conclusion}

Overall, an effective case management pathway is a collaborative process that involves service practitioners working alongside vulnerable communities to address risk and is an essential part of an agency's service delivery, providing the framework for successful interactions to take place. CFl's adoption of Save the Children's Steps to Protect system provided a consistent case management pathway well suited within a nascent child protection system, while still ensuring that services were delivered in a way that safely and sustainably reduced service dependency by impacting on practice culture. Incorporating case management into organizations in the Global South which provide health and welfare services provides an opportunity to engage in development and capacity-building rather than creating further dependency.

Acknowledgments: Eng Muyngim for providing the Khmer translation for the abstract. Family Care First / ReaCT for supporting the development of CFl's pathway.

\section{References:}

3PC. (2019). Partnership Programme for the Protection of Children. Retrieved $22^{\text {nd }}$ December 12019 http://3pc-cambodia.org/

Akyar, I. (2012). Standard Operating Procedures (What Are They Good For?) in Isin Akyar (ed). Latest research into quality control. Intechopen. DOI:10/5772/50439Barron, S., Damsleth, B., Ekvisoth, K., \& Nakkim, I. (2012). Guide to community-based child protection. Save The Children Norway. Retrieved $2^{\text {nd }}$ December 2020 https://resourcecentre.savethechildren.net/node/6806/pdf/6806.pdf

Braun, V., Clarke, V., Hayfield, N., \& Terry, G. (2019). Handbook of research methods in health social sciences. Springer.

Caceres, S., Yin, R., Tyrrell, A., Gaubatz, J., \& Williams, S. (2016). Introducing a framework for evaluating service delivery in sector evaluations: Urban transport, water and sanitation, and nutrition. World Bank, Washington DC, USA. 
Cooperation Committee for Cambodia (CCC). Frequently asked questions. Retrieved 3rd February 2020. https://www.ccc-cambodia.org/en/about-us/faq

Cannon, M., \& Snyder, E. (2012). The Child Status Index Usage Assessment [SR-1268]. Chapel Hill, NC: Measure Evaluation

Carter, R. (2019). Strengths-based practice: the overlaps between improving social work and managing resources. Community Care. June. Retrieved $1^{\text {st }}$ March 2020 https://www.communitycare.co.uk/2019/06/24/strengths-based-practice-the-overlapsbetween-improving-social-work-and-managing-resources/

Children's Future International, (2019). What We Do. Retrieved 3 January 2020 https://www.childrensfuture.org/what-we-do/

Child Welfare Information Gateway. (2019). Multidisciplinary teams. Retrieved $3^{\text {rd }}$ March 2020 https://www.childwelfare.gov/topics/responding/iia/investigation/multidisciplinary/

Cooper, F. (2012). Professional boundaries in social work and social care. Jessica Kingsley Publishers, London. Retrieved $1^{\text {st }}$ March 2020 http://www.respitenow.com.au/uploads/3/9/0/3/39035687/boundaries for carers.pdf

Drewery, W., \& Clainorne, B. (2014). Young adults. In human development: Family, place, culture. McGraw-Hill Education Pty Ltd.

Family Care First/REACT. (2019). Retrieved 22 $2^{\text {nd }}$ February 2020 https://www.fcfreact.org/

Featherstone, B., White, S., \& Wastell, D. (2012). Ireland's Opportunity to Learn from England's Difficulties? Auditing Uncertainty in Child Protection. Irish Journal of Applied Social Studies, 12(1) 5.doi:10.21427/D7RQ89

Freeman, M. (2009) Children's Rights as Human Rights: Reading the UNCRC. In: Qvortrup, J., Corsaro, W., \& Honig, M. (eds) The Palgrave Handbook of Childhood Studies. Palgrave Macmillan, London. https://doi.org/10.1007/978-0-230-27468-6_26 
Ferenczi, S., Csakvari, J., \& Tanczos, E. (2015). Vulnerability and resilience in early childhood interventions. International Conference on Education and Social Sciences. 2-4 February 2015- Istanbul, Turkey.

Fronek, P., Common, R., Smith Rotabi., K \& Statham, J. (2019). Identifying and addressing risk in the implementation of alternative care policies in Cambodia. Journal of Human Rights and Social Work. https://doi.org/10.1007/s41134-018-0087-y

Gillingham, P. (2006). Risk assessment in child protection: problem rather than solution? Australian Social Work, 59(1), 86-98.

Hall, J., Carswell, C., Walsh, E., Huber, D., \& Jampoler, J. (2002). lowa Case Management: Innovative Social Casework. Social Work, 47 (2) 132-141.

Harnett, P., \& Day, C. (2008). Developing pathways to assist parents to exit the child protection system in Australia. Clinical Psychologist, 12(3), 79-85. doi: $10.1080 / 13284200802495479$

Harvey. P., \& J. Lind. (2005). Dependency and humanitarian relief. A critical analysis. Overseas Development Institute.

Henley, L, J., Lowe, S., Henley, Z., Munro, C., Chan, C., Chhong, C., Hach, H., Hor, S., Kea, S., Mork, R., Pheun, S., Pras, S., Noue S. \& Song, L. (2019). International social work placements: Can overseas students stimulate professional learning for NGO staff? Advances in Social Work and Welfare Education, 21(1)21

Malena, C., Chhim, K., Hak, S., Heang, P., Chhort, B., Sou, K., \& Heng, K. (2009). Linking citizens and the state: An assessment of civil society contributions to good governance in Cambodia. World Bank Cambodia Country Office. Retrieved $3^{\text {rd }}$ February 2020 http://documents1.worldbank.org/curated/en/398781468222011480/pdf/491470WP0Box 331BLIC10CCSA1Eng1Final.pdf

Measure Evaluation. (2019). Child Status Index Tool. Retrieved $2^{\text {nd }}$ February 2020 https://www.measureevaluation.org/resources/tools/ovc/child-status-index 
McCormick, C. (2011). Case management practice within Save the Children child protection programs. United Kingdom: London: Save the Children UK. Retrieved the $22^{\text {nd }}$ of December 2019: https://resourcecentre.savethechildren.net/node/5207/pdf/5207.pdf

Morris, K \& Connolly, M. (2012). Family decision making in child welfare: Challenges in developing a knowledge base for practice. Child Abuse Review, 21, 41-52.

Partnering for Safety. (2020). Principles of the Partnering for Safety Approach. Retrieved $6^{\text {th }}$ March 2020 https://www.partneringforsafety.com/principles-of-pfs.html

Pearce, O. (2019). What are SOPs and why does my organization need them? Retrieved $31^{\text {st }}$ March 2020 https://blog.montrium.com/experts/what-are-sops-and-why-does-myorganization-need-them

Pulla, V. (2017). Strengths-based approach in social work: A distinct ethical advantage. International Journal of Innovation, Creativity and Change, 3, (2) 3.

Roche, S., \& Flynn, C, (2020). Geographical inequity in social work research: A snapshot of research publications from the global South. International Social Work, 63(3) 306-322. doi.org/10.1177/0020872818797999

Rogers, M., \& Parkinson, K. (2018). Exploring approaches to child welfare in contexts of domestic violence and abuse: Family group conferences. Child \& Family Social Work, 23(1)105-112.

Ross, S., Curry, N., \& Goodwin, N. (2011). Case management. London: King's Fund.

Sahoo, S. (2013) Doing development or creating dependency? NGOs and civil society in India, South Asia: Journal of South Asian Studies. DOI: 10.1080/00856401.2012.743500

Save The Children, Australia. (2014). Evaluation of Save the Children's child protection interventions in Cambodia, Lao PDR and Solomon Islands and their appropriateness to system strengthening. Child Frontier Ltd. Retrieved $4^{\text {th }}$ February 2020 https://resourcecentre.savethechildren.net/node/10260/pdf/save the children australia cp systems evaluation report.pdf 
Save The Children. (2019). Family Care First / REACT. Family Strengthening A collection of Promising Practices. International Child Development Initiatives. Retrieved $2^{\text {nd }}$ February 2020 https://www.childrensfuture.org/wp-content/uploads/2020/01/FCFREACT-Promising-Practices-Review FINAL-1.pdf

Save the Children. Toolkit: Steps to Protect - A common approach to case management. Save the Children. Retrieved 24 th of February 2020 https://resourcecentre.savethechildren.net/node/13223/pdf/common_approach_catalog ue_2018_online_version.pdf

Signs of Safety. (2019). Retrieved 23 $3^{\text {rd }}$ February 2020 https://www.signsofsafety.net/signs-of-safety/ 23/2/20.

Stanley, T. (2013). Our tariff will rise: Risk, probabilities and child protection. Health, Risk \& Society, 15 (1), 67-83. doi.org/10.1080/13698575.2012.753416

Stanford, V. (2015). Aid Dependency: The Damage of Donation. This Week in Global Health. Retrieved $9^{\text {th }}$ January 2020 https://www.twigh.org/twigh-blogarchives/2015/7/31/aid-dependency-the-damage-of-donation

Strier, R., \& Binyamin, S. (2013). Introducing anti-oppressive social work practices in public services: Rhetoric to practice. British Journal of Social Work, 44(8), 2095-2112. doi: 10.1093/bjsw/bct049

Strydom, M., \& Schiller, U. (2019). The transferability of family assessment tools between countries: Reflections on the intervention research approach. Child Abuse Review. https://doi.org/10.1002/car.2569

Tsui, M., \& Yan, M. (2010) Developing social work in developing countries: Experiences in the Asia Pacific region. International Social Work, 53(3) 307-310

UNDP (United Nations Development Programme) (2013). Human Development Report 2013 - The Rise of the South: Human Progress in a Diverse World. New York: UNDP. 
Retrieved $20^{\text {th }}$ January $2020 \mathrm{http}: / /$ hdr.undp.org/en/en/content/human-developmentreport-2013

UNICEF (2017). Integrating case management for vulnerable children - A process guide for assessing and developing an integrated case management system in Eastern and $\begin{array}{lllll}\text { Southern } & \text { Africa. } & \text { Retrieved } & 22^{\text {nd }} & \text { December }\end{array}$ http://www.socialserviceworkforce.org/resources/integrating-case-managementvulnerable-children-process-guide-assessing-and-developing

Waldfogel, J. (1998). Rethinking the paradigm of child protection. The Future of Children, $8(1), 104-119$.

Ward, J. (2011). Working with the Health Sector to Address Violence against Women and

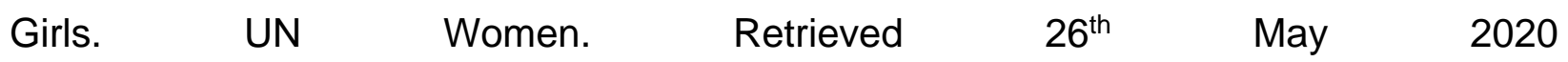
http://www.endvawnow.org/uploads/modules/pdf/1405612448.pdf

WHO (2018) Continuity and coordination of care: A practice brief to support implementation of the WHO Framework on integrated people-centred health services. Retrieved 28th of May 2020 from: https://apps.who.int/iris/bitstream/handle/10665/274628/9789241514033-eng.pdf?ua=1 